Author accepted preprint

McGlashan, M. (2021) Networked discourses of bereavement in online COVID-19 memorials. International

Journal of Corpus Linguistics. 26(4)

\title{
Networked discourses of bereavement in online COVID-19 memorials
}

\author{
Mark McGlashan \\ Birmingham City University
}

This paper reports on study of online COVID-19 memorials posted during 2020 to the Church of England website https://www.rememberme2020.uk/. The paper employs a Corpus-Assisted Discourse Studies (CADS) approach to analyse networks of cooccurring linguistic items (types and lemmata) and patterns (ngrams) within online memorials, and examines how these frequent items/patterns exist within networked discourses that underpin an overarching bereavement discourse. The analysis finds that bereavement discourse is underpinned by frequent reference to love, relationships and relational identification, time and temporality, loss/absence, and memory, as well as metaphors based on CONTAINER and JOURNEY image schema. An analysis of these metaphorical representations of death and bereavement suggest that online memorials serve as a space for the social practice of bereavement and shows how the language used to grieve attempts to ideologically (re)present the relationships between the bereaved and decedent. All code used in this paper can be found at https://osf.io/khcj2/.

Keywords: Bereavement discourse, memorials, COVID-19, corpus-assisted discourse studies

\section{Introduction}

COVID-19 is a deadly infectious disease that, at the time of writing (27/05/2021), has claimed the lives of approximately 3.5 million people worldwide and over 150,000 people in the UK (European Centre for Disease Prevention and Control, 2021). The enormity of this scale of deaths has been accompanied by national governments taking various, significant actions to 
Author accepted preprint

McGlashan, M. (2021) Networked discourses of bereavement in online COVID-19 memorials. International

Journal of Corpus Linguistics. 26(4)

prevent further spread through imposing nationwide lockdowns; prescribing physical ('social') distancing, sanitation, and face coverings in public places; and banning and/or restricting large gatherings like weddings, festivals, and funerals. As such, COVID-19 has had a profound influence on the public social lives of millions of people, including those rituals and practices related to end-of-life care and death. Tighter restrictions on physical visits with patients in UK hospitals and care homes have led to some patients becoming isolated and lonely, especially older patients unfamiliar with - or without access to - communications technologies. These restrictions have also meant that many people have been unable to say their final goodbyes to friends, family, and loved ones. Funerals have been live-streamed and certain traditional practices have had to be adapted or foregone, such as burial rites like ritual bathing required for traditional Islamic funerals (Hirji et al., 2020). And, although not a completely new phenomenon, online memorials have emerged as an important site for the collective practice of mourning as a response to the constraints of the COVID-19 pandemic, further highlighting the increasingly important role that the internet is playing in contemporary bereavement practices (Bell et al., 2015; Refslund Christensen \& Gotved, 2015; Lingel, 2013). The Church of England's website https://www.rememberme2020.uk/ emerged specifically as an "on-line book of remembrance for all those who have died as a result of the COVID-19 pandemic in the UK" as part of the Remember Me project, wherein the general public were invited to contribute small messages (memorials) in memory of the deceased.

This paper reports on a study of 5,026 online memorials published to the Remember Me website during 2020. The creation and use of an online memorial in response to the COVID-19 pandemic reflects an increasing shift in bereavement practices - as is true of many other aspects of contemporary social life - towards the online. Online memorials like Remember Me, therefore, represent potentially increasingly important cultural sites where practices of bereavement and remembrance are (re)produced and (re)invented, and, so, important sites for the empirical study of bereavement discourse.

\section{Language and online bereavement discourse}

Public notices of death are importantly and inherently social and, as instances of 'bereavement discourse', the various ways in which death may be memorialised (as, inter alia, epitaphs, eulogies, death notices, memorials, obituaries, etc.) have been studied from a wide variety of disciplinary perspectives (see Davis et al., 2016). Recognised in the literature are the various 
Author accepted preprint

McGlashan, M. (2021) Networked discourses of bereavement in online COVID-19 memorials. International

Journal of Corpus Linguistics. 26(4)

important social functions that bereavement discourse enables the living to enact and perform. Memorials can form a part of the bereavement process (Phillips, 2007: 326) by providing consolation to audiences and for the bereaved a medium for narrative reflection/reconstruction (Neimeyer, 1998; Neimeyer et al., 2014; Neimeyer et al., 2002) and an opportunity to construct new, positive meanings for themselves (Dennis \& Kunkel, 2004; Kunkel \& Dennis, 2003). As a response to death, instantiations of bereavement discourse like memorials "allow the living to socially frame death" (Williams, 2003: 701), whereby the living report on "what is considered important about the life of the decedent" (Phillips, 2007: 325). Memorials provide a textual framing for socially performing and sharing the process of grief, which "is basically a quest to re-establish life as a meaningful structure without the deceased and to heal the personal, social, and cultural gap that the death of this person has left behind" (Refslund Christensen \& Gotved, 2015: 6). Thus, as "a communicative process of framing and sensemaking" the content of memorials represents relational performances that discursively (re)construct social identities and relationships for their audience (Davis et al., 2016: 316).

Just as many other aspects of contemporary social life have become digitally mediated and shared, so too has death; "virtual memorials are quickly becoming part of our society's death and dying rituals" (DeGroot, 2014: 79; Jones, 2004). This move towards embracing tools that facilitate online memorial, which "offer a lot of opportunities for communicating, remediating, and sharing the hard times of loss and bereavement" (Refslund Christensen \& Gotved, 2015: 4), is reflected in a growing academic interest in the existence and use of online memorials, shrines, cemeteries, etc. as well as social media as places where practices and rituals associated with bereavement can be carried out and adapted. As Walter (2015: 227) notes:

Online, addressing the dead is done in the knowledge that there is a living audience which, by accepting such direct address and even actively joining in, legitimates a practice about which hitherto some people may have felt somewhat embarrassed, and it informalises traditions of addressing the dead via the newspaper; so much so that addressing the dead informally has on many sites become a new norm.

Researchers working within what has been described as "the growing field of death online research" (Giaxoglou, 2015: 56) such as Refslund Christensen \& Gotved (2015: 6) argue that the increasing use of online bereavement strategies reflect the important social aspect of grieving processes and that the inherently social mechanics of social media sites and other online tools enable audiences ranging from immediate family to complete strangers to engage 
Author accepted preprint

McGlashan, M. (2021) Networked discourses of bereavement in online COVID-19 memorials. International

Journal of Corpus Linguistics. 26(4)

in and foster intimate acts of mourning (Meyrowitz, 1994: 64; Walter, 2015: 226). As noted by Roberts (2004: 41), “[w]eb memorials allow the bereaved to honour the dead in their own way and at their own time, to visit the memorial whenever they choose, and to share memories and information about the deceased person."

Studies of contemporary (online) bereavement discourse have explored how people, amongst other things, cope with death as a social taboo (Crespo-Fernández, 2011), communicate grief and loss (Doka, 1987; Harvey, 1996), (re)present death and the dead in language (Davis et al., 2016), and how (re)presentations of death may vary diachronically (Anderson \& Han, 2008; Ergin, 2012; Rodler \& Hölzl, 2002; Fries, 1990; Phillips, 2007), appraise the dead and their lives (Dennis \& Kunkel, 2004), construct relational identities with the dead (Neimeyer et al., 2014; Kunkel \& Dennis, 2003), and construct death in response to diseases like HIV/AIDS (Roque Ramírez, 2010; Alali, 1994; Williams, 1997).

Although the language of bereavement discourse has been studied from numerous perspectives and most of these studies deal with written language data, there are few studies that take an explicitly linguistic approach. Those studies that do take a linguistic approach have focused primarily on figurative language, euphemisms and metaphor (Crespo-Fernández, 2007, 2011). In their linguistic study of obituaries, Crespo-Fernández (2006, 2007) outlines two types of obituaries. The first type are 'informative' obituaries "whose primary aim is the transmission of relevant details about the death, the deceased or the place and time or the funeral" (Crespo-Fernández, 2006: 9-10). The second type - 'opinative' obituaries - are "personal and intimate notices devoted to producing a particular effect of the readers by stressing social status, virtues or religious fervour of the deceased" (Crespo-Fernández, 2006: 10). Where informative obituaries "tend to be objective, impersonal and highly formulaic and standardized" (Crespo-Fernández, 2007: 10) in their use of language, opinative obituaries "are oriented towards causing a favourable impression on the reader by showing the social status or the exemplary conduct of the deceased" (Crespo-Fernández, 2007: 10). Crespo-Fernández suggests that opinative obituaries are marked by emotive, intimate and complimentary language and draw on a range of figurative, hyperbolic, and positively/negatively loaded words. Heynderickx \& Dieltjens (2016) find similar linguistic strategies being employed in their analysis of 150 obituaries published in Flemish staff magazines. In these obituaries, pronouns (especially first person pronouns) were used by authors to "stress how they feel about the decedent", hyperbolic "laudatory language" is found in descriptions of positive (professional or personal) qualities of the decedent, and figurative language was found in the use of euphemisms, which are used to "shy away" from the taboo topic of death and avoid 
Author accepted preprint

McGlashan, M. (2021) Networked discourses of bereavement in online COVID-19 memorials. International

Journal of Corpus Linguistics. 26(4)

"negative aspects" of death such as explicit references to cancer or suicide (Heynderickx \& Dieltjens, 2016). These euphemisms, used to "veil negative content and to console the readers" and as a "denial of death", include metaphors wherein the target domain DEATH is conceptualised through source domains of JOURNEY, LOSS, REST/SLEEP, A JOYFUL LIFE, A CALL FROM GOD, and THE END (see Crespo-Fernández, 2011).

Finally, Giaxoglou (2015) has studied language in online tributes to the loss of a young adult found in a Rest in Peace (R.I.P.) group on the social media website Facebook. Giaxoglou's examination of a series of posts by a single user on this group found that specific time and space deixis can serve to 'entextualize' (i.e. semiotically represent or encode through the production of texts) events, identities, relationships, and (affective) attitudes in the social experience of mourning. Giaxoglou (2015) found that "[s]tatic deictics" such as here (space), then (time) and we (person) were used to 'anchor' mourning to specific times (e.g. "last night", "tonight") and to relate - but contrastively separate - the spatial positionings of the mourner and the bereaved in ways that "separate the here and not-here (or "up there")". On the other hand, dynamic deictics such as "every night" or "everyday" (temporal) and "everywhere" (spatial) that "point at [...] movement in space (hither), developments in the course of time (from now on) or events that take place between persons ('I-him')" were found to "[point] to repeated (inter) action in a futurate present" in ways that "serve to locate the sharer among a group of mourners committed to continued, everyday remembrance" (Giaxoglou, 2015: 61). A smaller amount of research deals with bereavement discourse from any kind of quantitative perspective. Phillips (2007), for example, examined 470 obituaries collected from the newspaper The New York Times published in the years 1899, 1959, and 1999 to examine changing conceptions of death over time. He found evidence that 'death-affirming language' "any language in an obituary that allows the observer to reconstruct the final biophysical narrative of a decedent through the circumstances that ultimately culminate in death" - has been increasingly omitted in favour of 'death-resistant language' - "language that editorializes or places death and the process of dying in a particular normative context" (Phillips, 2007: 334). More uncommon still is the application of corpus methods to study bereavement discourse, but small studies do exist, for example in Crespo-Fernández's (2013) work comparing the use of euphemisms across Spanish and English epitaphs in a small corpus of 312 tombstone inscriptions (172 in Spanish collected from Albacete cemetery, Spain and 140 in English from Highgate cemetery, London, UK).

This paper contributes to the literature on (online) bereavement discourse by addressing several gaps in the research. Firstly, although some research has examined the relationships 
Author accepted preprint

McGlashan, M. (2021) Networked discourses of bereavement in online COVID-19 memorials. International

Journal of Corpus Linguistics. 26(4)

between memorials and infectious diseases (Roque Ramírez, 2010; Alali, 1994; Williams, 1997), little (if anything) is yet known about the relationships between COVID-19 and linguistic practices related to bereavement. For example, although COVID-19 has forced bereavement practices online in a way perhaps never seen before, which has included the creation of numerous online memorials, including a page dedicated to Those We've Lost from The New York Times (The New York Times, 2021) and The Lives Lost to Coronavirus from TIME Magazine (Time Staff, 2021), there is no known work detailing the linguistic characteristics of these texts. Secondly, although (online) memorials have been studied in the past, they have not been so at any kind of quantitative scale. In response, through analysing 5,026 online memorials, the present paper aims to detail empirical, quantitative linguistic characteristics of online memorials. And thirdly, the paper extends CADS methods to the analysis of online memorials in order to investigate salient, quantitative and networked features of bereavement discourse. The following research questions guide this study to address these aims:

RQ1. What language is used in the online memorials corpus?

RQ2. What discourses around death and bereavement are evident in this language?

\section{Data}

The data for this study were collected on 17/06/2020 using a bespoke piece of webscraping software written in the programming language $\mathrm{R}$ ( $\mathrm{R}$ Core Team, 2014), which is designed to identify and scrape all memorials posted to https://www.rememberme2020.uk/. The webscraper relies on methods made available in the R package rvest (Wickham, 2021) which is designed for downloading and manipulating HTML and XML data from the web - much like any web browser - and makes navigating the HTML data from which websites are made fairly straightforward by providing methods for identifying and selecting HTML elements and attributes. Like many websites, https://www.rememberme2020.uk/ is organised into numbered pages that can be clicked through and viewed, with each page containing up to 100 entries. The web scraper identifies how many pages of memorials the website has in total and then iteratively visits each page of the website, identifies each individual memorial, and stores these memorials as separate row in a single large data. frame object (similar to a spreadsheet) for analysis. For purposes of reproducibility, replicability, and transparency (Marchi \& Taylor, 
Author accepted preprint

McGlashan, M. (2021) Networked discourses of bereavement in online COVID-19 memorials. International

Journal of Corpus Linguistics. 26(4)

2018: 12), the web scraper and all other code used in this project for data collection and analysis can be found here: https://osf.io/khcj2/. By including complete details of the methods used in this study for data collection and analysis, the work invites future studies that adopt, adapt and extend the work presented here. Thus, I hope not only to stimulate responses to this specific paper but also to contribute more broadly to ongoing discussions within Corpus Assisted Discourse Study (CADS) ${ }^{1}$ about how and why our work should foster and encourage transparency with a view towards embedding accountability (Marchi \& Taylor, 2018: 12) within CADS.

Data were collected in line with ethical guidelines set out by the British Association for Applied Linguistics (BAAL) on the use of data from open-access websites, which BAAL considers to be in the public domain and available for analysis given due concern for user privacy and dignity. Although personally identifiable information (such as names and dates of birth and death) about the memorialised is made freely and publicly available by users of the website, the names of the deceased are excluded during data collection to attempt to preserve their anonymity. Moreover, the methods employed during analysis deal with only the most frequent linguistic features found in an aggregate of memorial texts to prevent focus on any single memorial in isolation, which could result in personally identifiable information being republished or shared outside of its original context.

The data collection for this study yielded a corpus of 5,026 memorials. Although this number of texts is relatively small for a study in corpus linguistics, these memorials represented a sizeable proportion $(11.7 \%)$ of the 41,969 people that were reported as having died from COVID-19 in the UK at the time of data collection; the British Social Attitudes survey reported in 2018 that $12 \%$ of the UK's religious population identify as Church of England. ${ }^{2}$ Combined, these two metrics begin to give some idea of the corpus' scale and its potential representativeness of bereavement discourse concerning those who have died as a result of COVID-19 in the UK.

With sense of the size of the corpus in terms of number of texts, the contents of those texts can be explored in finer detail. The R package quanteda (Benoit et al., 2018) provides a range of methods for the quantitative analysis of textual data and is used throughout this paper for analysis. In the first instance, memorials are required by quanteda to be coerced to a corpus

\footnotetext{
${ }^{1}$ I adopt the acronym CADS to refer to a now well-established field of research combining and applying methods, tools and approaches from corpus linguistics and discourse studies. However, I do not align the present study with any particular approach to corpus-assisted discourse analysis.

${ }^{2}$ https://www.bsa.natcen.ac.uk/media/39293/1_bsa36_religion.pdf
} 
Author accepted preprint

McGlashan, M. (2021) Networked discourses of bereavement in online COVID-19 memorials. International

Journal of Corpus Linguistics. 26(4)

object for further analysis. Prior to coercing to a corpus, I removed Unicode emoji codes. Before being rendered by browsers as an image, emojis appear as strings of Unicode characters such as $\langle\mathrm{U}+2764\rangle$ - the code for a red heart ( $)$ emoji - and are found across several memorials, as in Example (1).

(1) A sociable, generous, loving Dad and Grandad. Always and forever in our hearts $<\mathrm{U}+2764>$

Although these emojis may reveal something about discourse practices made possible through computer mediated, online platforms for bereavement, and might well provide a fruitful avenue for future research into multimodal discourses of bereavement, emoji codes were excluded here in order to focus the analysis on word tokens in the corpus. Similarly, corpus text had punctuation removed and was transformed to lowercase so that punctuation and case would not inadvertently influence token frequency counts. Following these protocols, the corpus was found to be 143,305 tokens in size. Furthermore, the range and average token size of memorial can be calculated and visualised using some base $\mathrm{R}$ functions to show the length of memorials (in terms of token number) and how memorials of different token lengths contribute to the overall makeup of the corpus.

\section{INSERT FIGURE 1 HERE}

Figure 1. Histogram showing distribution of individual text sizes (in tokens) in the corpus

The histogram in Figure 1 displays the "shape" of the corpus in terms of text sizes (in tokens) and shows that memorial texts are short in general, with the text population being most densely concentrated around the $3^{\text {rd }}$ quantile (38 tokens); the mean text length is 28.51 tokens. The length of bereavement discourse texts has been infrequently discussed in the literature but Williams (2003), for example, has argued that death notices are typically 100-150 words in length, and Heynderickx \& Dieltjens (2016), in their study of 150 obituaries (42,445 words in total) in corporate staff magazines, found that obituaries were 282.97 words on average (mean). The differing lengths found across these studies (including the present paper) may reflect the kinds of texts and contexts in which bereavements are reported (e.g. online or offline), the affordances of those texts/contexts, or intended audiences, etc. rather than some general feature of bereavement discourse texts. However, the relationships between text length and context and the differences observed may also constitute worthwhile avenues for future research. 


\section{A corpus-assisted approach to identifying networked discourses}

The present study is informed by the theoretically and methodologically pluralistic approaches being taken in the growing body of research employing methods, techniques, and tools associated with corpus linguistics to study linguistic and discursive patterning across collections of linguistic data large enough to warrant quantitative investigation. Various names have been given to such studies, including corpora and discourse studies (Baker \& McEnery, 2015), Corpus-Assisted Discourse Studies (CADS; e.g. Partington, 2004), corpus-based discourse analysis (Flowerdew, 2014), corpus-based CDA (Baker et al., 2008), and DiscourseOriented Corpus Studies (DOCS; Gabrielatos, 2020; but see Marchi \& Taylor, 2018). However, all are concerned with synthesising, combining, and shuffling between the methods, approaches, theories, tools, frameworks, etc. associated with both corpus linguistics and (critical) discourse analysis to provide at once qualitative and quantitative insights about the workings of discourse.

The present study, like a large amount of work in CADS, concentrates on the analysis of a specialised corpus (e.g. Baker \& McGlashan, 2020). Specialised corpora, noted as being "particularly useful in discourse analysis" (McEnery et al., 2006: 111), are compiled using extremely specific sampling criteria and are often designed to be as representative of a particular variety of language, topic, register, genre, etc. as possible, if not entirely representative. As the present study employs a total population sampling method, the resultant specialised corpus contains every memorial posted to the Remember Me website and is entirely representative of the population under study (at the point of collection). However, such specialisation has its limitations in that this corpus can only be used to make observations about language used in these specific texts and in this specific context.

Again, like a large amount of work in CADS, the present study uses computers to identify (in)frequent patterns of language use, observations on which serve to facilitate more qualitative interpretations of how those (in)frequent patterns function within a discourse and across texts (Baker \& McGlashan, 2020). As such, this paper takes a corpus-driven - as opposed to a corpus-based - approach (Tognini-Bonelli, 2001) to the study of bereavement discourse by exploring frequency lists, which "can be helpful in revealing common patterns or themes in corpora" (Baker, 2014: 13) as starting points for analysis. 
Author accepted preprint

McGlashan, M. (2021) Networked discourses of bereavement in online COVID-19 memorials. International

Journal of Corpus Linguistics. 26(4)

Like many corpus-driven studies of discourse the first point of analysis here is the derivation of frequency lists. Here, I focus on frequency lists of types, lemmata and ngrams, "sequences of $n$ elements (usually words) that occur directly one after another in a corpus, where $n$ is two or more" (McEnery \& Hardie, 2012: 247). Ngram analysis is limited to a consideration of consecutive sequences of 3 tokens (trigrams), which enables the study of frequent formulaic phrasal patterns beyond the level of the token, but also the ability to operationalise the notion of collocation at the level of the ngram (i.e. collocation between ngrams). When analysing frequency lists, only 20 items are given here to "peek" at the data to find out what features are overwhelmingly frequent in the corpus and as a starting point for analysis rather than constituting an analysis in and of itself.

Following Sunderland's (2004) conceptualisation of discourse - which suggests that a discourse is supported by an accumulation of related, supporting, "bricked together" (Sunderland 2004: 31) discourses - this paper conceives of bereavement and mourning as socially and linguistically represented, negotiated, constructed, or otherwise done and instantiated in and as a variety of discourses associated with death that (can) interact within a range of "networked discourses" (Sunderland 2004: 31) that coalesce and underpin an overarching bereavement discourse. This notion of discourse echoes the suggestion that all discourse practices are, in some way, related through 'orders of discourse' (Fairclough, 2003) and that discourses coalesce in unique and specific ways for particular 'fields of action', within institutions, for particular events, etc. In order to explore dominant discourses associated with bereavement, this paper takes the notion of networked discourses somewhat literally and explores how frequently used linguistic items and structures might co-occur with each other as part of a wider linguistic network when used in memorial texts. Exploring networks will simultaneously enable exploration of what language is used in online memorials (RQ1) as well as exploration of discursive relations evident in networks of co-occurring linguistic items and what these suggest about death and bereavement in memorials (RQ2).

Corpus methods for identifying patterns of linguistic co-occurrence (predominantly through collocation) are often employed to examine salient associations that may be ideologically (thus, discursively) revealing. As Baker (2006: 13) notes about collocation, "an association between two words, occurring repetitively in naturally occurring language, is much better evidence for an underlying hegemonic discourse which is made explicit through the word pairing than a single case". Wright \& Brookes (2019), for example, have employed collocation analysis to identify how the British right-leaning press talk about people in the UK (not) speaking English, finding that these people are represented in largely negative ways (e.g. as 
Author accepted preprint

McGlashan, M. (2021) Networked discourses of bereavement in online COVID-19 memorials. International

Journal of Corpus Linguistics. 26(4)

displacing 'native' British people, as economically burdensome, and as a (cultural) threat). Collocation networks, which illustrate a network of associations between linguistic features in a corpus, have been increasingly explored as a method for visualising and conceptualising collocational relationships between types in a corpus (Brezina et al., 2015; Baker, 2016). That is to say these networks may be useful in identifying repeated and systematic associations between linguistic items in naturally occurring language data. In the service of identifying (repeated) associations between linguistic features that may interact with each other in the entextualisation (Giaxoglou 2015) of the social practice of bereavement (what I will refer to here as networked discourses of bereavement), this paper extends the idea of collocation networks by exploring networks visualising linguistic co-occurrence in individual memorial texts. This approach is similar to the work done by Brookes \& McEnery (2020) in their work examining a corpus of 'ideologically loaded' violent jihadist texts where they were able to show that correlations between words in a text contributes to textual cohesion, but also that repeated correlations across texts serve important discursive functions vis-à-vis identity (re)presentation and the (re)articulations of ideology. As such, the present paper examines how frequent and repeated linguistic co-occurrences might shed light on the workings of discourse in and across memorial texts.

The networks explored in this paper visualise the co-occurrence relationships within individual memorial texts between the top 50 most frequent features of a frequency list. A feature co-occurrence matrix is built for the whole corpus, which counts the number of cooccurrences between features (i.e. types, lemmata, ngrams) in each memorial, the visualisation of which is limited to the top 50 most frequent features. Each node - points labelled by features (types, lemmata, ngrams) - is sized to show the proportional frequency of that feature within the top 50 features being visualised. Nodes are connected by edges (i.e. lines), the width of which shows how frequently nodes collocate with each other and the length of distance is weighted by span. Features that co-occur really frequently and within a narrower span have wide edges and are positioned more closely together, with the opposite being true for features that co-occur less frequently and within wider collocational windows. Through combining 'peeks' into frequency lists with analyses of collocation networks, the methods adopted aim to identify (a)typical patterns of language use that may indicate discursive norms or ideologies what Baker (2006: 13) refers to as the incremental effect of discourse - within a specialised corpus of texts dealing with the contentious taboo of death and thus to understand how language figures in social, discursive constructions/understandings of death and the dead in online memorials. 


\section{Discussion}

This section presents initial descriptive analyses of type, lemma and ngram frequencies in the memorials corpus to facilitate identification of some of those networked discourses that underpin bereavement discourse, before moving on to a fuller discussion of their discursive functions.

\subsection{Frequent types}

As with almost any other English language corpus, many of the most frequent types in the memorials corpus as shown in Table 1 are grammatically closed-class words (e.g. pronouns, conjunctions, prepositions). However, Table 1 also shows that some grammatically open-class words with some semantic content (e.g. missed, forever), including some terms that share the same lemma LOVE (love, loved, loving) do appear in the most frequent overall types in the corpus, which, to some extent, may reflect the size of the corpus (and its composite texts [Table 1]) as well as the specific topic of the corpus.

Table 1. Type frequency list, ranked by frequency

\begin{tabular}{llllllll}
\hline Rank & Feature & Frequency & Texts & Rank & Feature & Frequency & Texts \\
\hline 1 & and & 7930 & 4004 & 11 & be & 1887 & 1672 \\
2 & you & 4459 & 2323 & 12 & love & 1798 & 1610 \\
3 & a & 3953 & 2608 & 13 & loved & 1757 & 1575 \\
4 & in & 3668 & 2731 & 14 & always & 1692 & 1486 \\
5 & to & 2688 & 1783 & 15 & missed & 1691 & 1662 \\
6 & our & 2665 & 2009 & 16 & loving & 1657 & 1547 \\
7 & will & 2607 & 2202 & 17 & all & 1554 & 1366 \\
8 & of & 2473 & 1923 & 18 & was & 1550 & 1150 \\
9 & we & 2216 & 1596 & 19 & forever & 1389 & 1308 \\
10 & the & 2194 & 1662 & 20 & by & 1375 & 1268 \\
\hline
\end{tabular}




\section{INSERT FIGURE 2 HERE}

Figure 2. Network of top 50 most frequent types

Visualising the collocational relationships between the top 50 most frequent types as a network shows the centrality and importance of grammatical items to the language being used. Although grammatical items tend to be used at a high frequency across most English genres and registers, the second person personal pronoun you and the first person plural pronouns we and our are extremely frequent and are closely networked, suggesting that writers use memorials to address the deceased directly and on behalf of a group with which the writer aligns themselves (e.g. We will all miss you forever, we will always remember you). Other pronouns (e.g. his, she, us) are also less frequently found and tend to be used in more indirect memorials (e.g. she loved her family and we all loved her). But the network in Figure 2 also begins to suggest some lexical groupings that may potentially be important features in discourses of bereavement, including:

i. Relational identification (van Leeuwen, 2008) as suggested by frequency of kinship terms (e.g. dad, friend, husband, mother, mum, wife)

ii. Love (LOVE, hearts)

iii. Temporal adverbs (always, forever)

iv. Loss/absence (miss, missed)

v. Memory

These results reflect - and serve to validate - some of those findings already present in the study of (online) bereavement discourse such as those of de Vries \& Rutherford (2004) whose study of 244 online memorials posted to the website The Virtual Memorial Gardens, ${ }^{3}$ found that memorials often referenced missing decedents, featured direct address from author to the deceased rather than about/for the deceased, and avoided references to religion, god, or the causes of death. Moreover, as discussed in Section 2, the centrality of pronouns/person diexis to expressions of personal, emotional connections in memorials was also found by Heynderickx $\&$ Dieltjens (2016) and Giaxoglou (2015). The apparent preferance for forms of direct address over indirect address in this online context may, at once, draw on linguistic constructions

\footnotetext{
${ }^{3}$ http://catless.ncl.ac.uk/vmg/
} 
Author accepted preprint

McGlashan, M. (2021) Networked discourses of bereavement in online COVID-19 memorials. International

Journal of Corpus Linguistics. 26(4)

familiar to "traditional" bereavement texts like obituaries but also draw on more novel online practices geared towards 'public intimacy' (Kaplan, 2021) - the performance of intimate social relations in front of an unknown third party public other. Public intimacy has become central to online practices, especially relating to social media, for the 'concretization' and collective performance of social relations in non-face-to-face contexts and "creating a sense of mass community that is far from abstract and anonymous for it is based on growing familiarity between strangers" (Kaplan, 2021: 597). Directly addressing the deceased online may, therefore, serve to rearticulate, 'concretize', display, and perform social bonds, especially in a context where such mourning cannot take place as part of traditional offline rituals. Finally, overtly affective language (e.g. love, miss) and temporal adverbs, which serve as "affective positioning resources" (Giaxoglou, 2015) alongside person deixis, enable users to publicly position social and emotional bonds with the deceased as temporal constants.

\subsection{Frequent lemmata}

Having identified and examined some frequent grammatically closed- and open-class words (and offering some potential lexical groupings), lemmata are explored at this stage of analysis in a lemmatised version of the corpus as one possible method for concentrating analysis on grammatically open-class (or lexical) words within memorials. This approach would allow, for example, analysis of an English lemma such as DESTROY and all of its inflected forms (destroy, destroys, destroying and destroyed). Prior to lemmatisation, and in order to more directly focus on frequent lexical items that may perhaps give a better idea of discourses present in memorial texts, grammatical words were removed from the corpus using a stopword list ${ }^{4}$. Although the use of stopwords can arbitrarily elide linguistic features that can reveal important information about the language used in a corpus (like pronouns discussed in Section 5.1, for example), the present study attempts to explore frequent features in the corpus in a nuanced and targeted way by taking steps to present results of analysis that exclude stopwords in conjunction with those that do not. Furthermore, in aiming for full methodological transparency, readers are invited to adapt these methods and to test the effectiveness of including or excluding stopwords in their own analyses. ${ }^{5}$ As such, this stage of analysis identifies frequent lexical lemmata and examines

\footnotetext{
${ }^{4}$ Use quanteda: : stopwords ("en") to view the stopword list used here.

${ }^{5}$ https://osf.io/khcj2/
} 
Author accepted preprint

McGlashan, M. (2021) Networked discourses of bereavement in online COVID-19 memorials. International

Journal of Corpus Linguistics. 26(4)

networks of co-occurrence between these frequent lemmata within memorials. Repeated associations are taken to be potential evidence of the presence of a discourse related to bereavement and, insofar as these associations exist within a network, are also taken to be networked discourses of bereavement.

Table 2. Lemma frequency list, ranked by frequency

\begin{tabular}{llllllll}
\hline Rank & Feature & Frequency & Texts & Rank & Feature & Frequency & Texts \\
\hline 1 & LOVE & 5389 & 3747 & 11 & FAMILY & 1099 & 1025 \\
2 & MISS & 2720 & 2613 & 12 & FRIEND & 1085 & 1042 \\
3 & ALWAYS & 1694 & 1487 & 13 & MUM & 1066 & 933 \\
4 & HEART & 1546 & 1486 & 14 & FATHER & 904 & 866 \\
5 & FOREVER & 1389 & 1308 & 15 & GRANDAD & 889 & 674 \\
6 & GREAT & 1345 & 1184 & 16 & US & 878 & 775 \\
7 & DAD & 1318 & 1152 & 17 & X & 807 & 640 \\
8 & HUSBAND & 1257 & 1252 & 18 & PEACE & 660 & 653 \\
9 & MUCH & 1181 & 1084 & 19 & NEVER & 653 & 619 \\
10 & MEMORY & 1135 & 1074 & 20 & MOTHER & 643 & 611 \\
\hline
\end{tabular}

As well as further establishing the prominence of some lexical grouping found in Section 5.1 (e.g. relational identification, memory, temporal adverbs), the network in Figure 3 reveals a wider range of evaluative features than was previously identified. Along with highlighting affective features such as " $x$ " (commonly understood in British computer mediated communication a symbol for a kiss), the lemmatised corpus shows the semantically negative lemma SAD to be frequent as well as additional semantically positive lemmata (KIND, DEAR) alongside the already known to be frequent lemma LOVE. Here, with a dispersion (what quanteda calls docfreq) of 3,747, words relating to the lemma LOVE are found to be present in around $75 \%$ of all memorial texts in this corpus and, as shown in Figure 3, LOVE is found to be central to this network, connecting particularly frequently with lemmata related to relational identification (e.g. LOVE + MUM), memory (e.g. LOVE + MEMORY), and temporal adverbs (e.g. LOVE + FOREVER). In this graph, connections between the 50 most frequent lemmata start to reveal some frequent co-occurrences between lemmata independently of LOVE, too. For example, large edges between NEVER + FORGOTTEN, REST + PEACE, TAKEN + SOON, and SAD + MISS suggest consistent co-occurrence between these lemmata with individual memorial texts. Indeed, "never" occurs to the left of FORGOTTEN (within a span 3 words; L3) in 338 of 378 
Author accepted preprint

McGlashan, M. (2021) Networked discourses of bereavement in online COVID-19 memorials. International

Journal of Corpus Linguistics. 26(4)

(89.42\%) instances of in which FORGOTTEN is used in memorials. This includes lexical bundles like, for example, "never forgotten", "never be forgotten", and "never to be forgotten". Similarly, REST is found to occur within an L3 span of PEACE 76.63\% (459/599) of the time in epithets such as "rest in peace", which accounts for 70.2\% (420/599) of all co-occurrence between REST and PEACE, but also in formulations such as "rest in eternal peace". Relationships between TAKE + SOON and SAD + MISS occur in similarly formulaic ways and are revisited for analysis in Section 5.3 during an analysis of (networked) ngrams.

\section{INSERT FIGURE 3 HERE}

Figure 3. Network of top 50 most frequent lemmata

\subsection{Ngrams}

These final results present the frequency and networks of ngrams in the memorials. This analysis works with the original tokenised corpus and does not exclude stopwords. The same process was tested with the lemmatised corpus but differences in results were found to be negligible within the top 50 ngrams. Testing with stopwords resulted in an extremely sparse network as stopwords stripped too much grammatical information from the corpus for ngrams (as a phraseological approach) to make much sense.

The most frequent ngrams (Table 3) reflect some of those findings at the lexical level, including references to love both directly (e.g. we love you), as well as figuratively (e.g. in our hearts), links between ideas of love and memory (e.g. in loving memory, loving memory of), references to relational identification (family and friends), use of temporal adverbs (e.g. forever in our, will always be), and references to loss/absence (e.g. missed by all). Ngrams also reflect some of those relationships that analysis of the lemmatised corpus began to reveal (rest in peace) but further identifies some figurative expressions relating to death (we meet again), which I discuss further below and in Section 5.5. 
Author accepted preprint

McGlashan, M. (2021) Networked discourses of bereavement in online COVID-19 memorials. International

Journal of Corpus Linguistics. 26(4)

Table 3. Ngram frequency list, ranked by frequency

\begin{tabular}{llllllll}
\hline Rank & Feature & Frequency & Texts & Rank & Feature & Frequency & Texts \\
\hline 1 & in_our_hearts & 1034 & 1033 & 11 & always_in_our & 235 & 234 \\
2 & forever_in_our & 466 & 463 & 12 & you_so_much & 233 & 228 \\
3 & in_loving_memory & 425 & 425 & 13 & we_meet_again & 218 & 218 \\
4 & loving_memory_of & 421 & 421 & 14 & family_and_friends & 208 & 207 \\
5 & rest_in_peace & 420 & 419 & 15 & a_much_loved & 204 & 203 \\
6 & missed_by_all & 329 & 329 & 16 & be_in_our & 203 & 203 \\
7 & will_always_be & 293 & 283 & 17 & and_miss_you & 202 & 202 \\
8 & will_be_missed & 257 & 257 & 18 & you_will_always & 202 & 199 \\
9 & you_will_be & 242 & 239 & 19 & in_memory_of & 201 & 201 \\
10 & memory_of_a & 241 & 241 & 20 & we_love_you & 194 & 193
\end{tabular}

As with the networks previously explored, the corpus has been tokenised but is slightly different in form; the corpus remains a sequence of tokens but each sequential ngram token overlaps the previous and subsequent tokens as per Table 4 below. For example, in our hearts + our hearts forever $=$ in our hearts forever. As such, a network of these ngrams at once is able to show what kinds of ngrams are frequent and frequently co-occur, but also show - by tracing along edges between nodes - how ngrams may combine as part of larger phrasal units, as illustrated in Table 4 randomly sampled concordance lines of the most frequent ngram (in our hearts).

Table 4. A sample of 5 random concordance lines of the search term in_our_hearts in the ngram corpus

$\begin{array}{rll}\text { her_in_our } & \text { Node } & \\ & \text { in_our_hearts } & \text { our_hearts_always } \\ \text { in_our_hearts } & \text { our_hearts_and } \\ \text { forever_in_our } & \text { in_our_hearts } & \text { our_hearts_as } \\ \text { always_in_our } & \text { in_our_hearts } & \\ \text { always_in_our } & \text { in_our_hearts } & \text { our_hearts_x }\end{array}$

As well as elaborating some of those findings discussed earlier, the ngram network in Figure 5 visualises links at the phrasal level between prominent concepts. Linguistic associations between concepts like time, love and memory, for example, may be indicative of - or, at least, 
Author accepted preprint

McGlashan, M. (2021) Networked discourses of bereavement in online COVID-19 memorials. International

Journal of Corpus Linguistics. 26(4)

meaningfully related to - bereavement discourse. And because language affords innovation in the realisation or construal of discourses, the entextualisation of discourses of bereavement may possibly be achieved through various (and networked) linguistic associations (e.g. Figure 4).

\section{INSERT FIGURE 4 HERE}

Figure 4. A possible ngram sequence for in our hearts

Metaphorical expressions relating to death also appear evident in the network, some of which reflect those metaphors identified by Crespo-Fernández (2011) in their study of epitaphs, including metaphors for death based on the JOURNEY image schema (until we meet again), DEATH IS A REST/SLEEP (rest in peace), DEATH IS A LOSS (will miss you), and DEATH IS A CALL FROM GOD (taken too soon). However, prevalent in the network - and which is not discussed in other work - is the presence of CONTAINER metaphors where the decedents are kept in our hearts or in our thoughts. The discussion in Section 5.5 explores these metaphors in greater detail.

\section{INSERT FIGURE 5 HERE}

Figure 5. Network of top 50 most frequent ngrams

5.4 Memorials as social practice

The results given throughout Section 5 outline some of the most frequent types, lemmata, and ngrams used in the online memorials under study and reveal some of those networked linguistic relationships that underpin bereavement discourse. Prominent across the analysis of types, lemmata, and ngrams are the frequent presence of (and networks between) linguistic representations of love, relationships and relational identification, time and temporality, loss/absence, and memory. Such repeated and cumulative instances of these networked linguistic associations seem to evidence the presence of recurrent patterns which suggest an incremental effect of discourse concerning the discursive positionings of, associations with, and practices concerning death and bereavement. The regularity of use of, for example, idiomatic expressions like rest in peace identified during n-gram analysis, as well as the 
Author accepted preprint

McGlashan, M. (2021) Networked discourses of bereavement in online COVID-19 memorials. International

Journal of Corpus Linguistics. 26(4)

presence (and frequent associations between) love and memory are potentially indicative of (as well as dialectically shape) wider cultural conceptualisations and discourses of death and bereavement. These repetitious discursive acts give evidence of memorials as linguistic sites for the (re)constitution of performative practices of ritual and mourning. Furthermore, the analyses reveal clear evidence of relational performances achieved through direct address to decedents as well as through frequent representations of decedents in terms of their relational identities. That affirmation of the life of the dead and their relationships to the living are so frequent across memorial texts suggests their importance to textual and discursive instantiations of bereavement. This has been noted as being part of the content of memorials through which "a communicative process of framing and sensemaking" (Davis et al., 2016: 316 ) is done. So, texts like memorials represent relational performances that discursively (re)construct social identities and relationships for their (living) audience (Davis et al., 2016: 316) which, in so doing, performatively, publicly, and linguistically (re)instantiate and (re)enact these identities.

\subsection{Metaphor in memorials}

Given the suggestion that figurative language concerning taboos like death may reveal wider cultural beliefs (Crespo-Fernández, 2013: 103), the prominent use in the data of metaphors based on CONTAINER and JOURNEY image schema within a wider bereavement discourse network warrants further discussion about how such metaphors may be revealing of wider ideological conceptualisations of death.

Conceptual metaphors based on the CONTAINER image schema - wherein a container can be conceived of as a bounded physical or mental space (Charteris-Black, 2006: 575) - are found in the data in the forms MIND AS CONTAINER (in our thoughts, in memory of, in loving memory) and HEART AS CONTAINER (in our hearts), suggesting containment of the decedent by the bereaved in a bounded mental, physical, and/or emotional space; thus, tied to discourses of memory and love identified above. In the case of the HEART AS CONTAINER metaphor, Philip (2017: 224) suggests that the "'heart' is a body part, but when metaphorical it can be a location or an emotion - as encoded and identified in the syntax", for example, through the use of preposition in in the n-gram in our hearts, which could here be the case for both heart and mind 
Author accepted preprint

McGlashan, M. (2021) Networked discourses of bereavement in online COVID-19 memorials. International

Journal of Corpus Linguistics. 26(4)

container metaphors. CONTAINER metaphors imply both an inside (close) and an outside (distant) and an agentive process of containment, which

implies a conscious controlling entity that fills or empties the container [...]. Even when we think of the body as container, the bodily functions of what goes into or out of the container are both conceptualized as being under the control of a conscious entity. (Charteris-Black, 2006: 576-577).

In the case of bereavement discourse, the container's contents (the decedent) are close to the self, the heart/mind being part of the body (and the body as a container itself), the remembered become contained from the outside and forever sealed within a part of the self. The bereaved agent deliberately and consciously brings experiences and people from the outside to the inside, containing the dead within themselves. The data contain examples such as stay locked away in our hearts forever and we hold you in our hearts and memories, which figure the deceased patient of containment as something to be held, carried, cherished, and locked away, as being placed within a special place in our hearts. Although the dominant usage of in our hearts in the data, this ngram is also found to be used in other metaphorical constructions such as you have left a big hole in our hearts, which shows that this construction can also figure in JOURNEY metaphors.

DEATH IS A JOURNEY metaphors have been found in previous research which suggests that this mapping mitigates the taboo of death (Crespo-Fernández, 2011). These journeys include DEATH IS REST metaphorical construction (e.g. the euphemism rest in peace). Additionally, DEATH IS A JOURNEY metaphors make possible the mapping of roles related to the source domain onto death, for example by positioning the dead and living as travellers on the same journey (until we meet again). Relatedly, they enable mappings of events/actions that occur on journeys, such as departures which are performed by or "on the part of some causal agent - someone who brings about, or helps to bring about, departure" (Lakoff, 1993: 232). DEATH IS DEPARTURE metaphors are present within the data in examples such as until we meet again, wherein travellers depart on different paths before being reunited later in their journeys, and/or in constructions where the decedent is positioned as having been compelled to depart (e.g. taken too soon, taken from us). Crespo-Fernández (2011) has previously interpreted formulations such as taken too soon as DEATH IS A CALL FROM GOD and suggested that the elision of direct reference to the cause of death is a feature of opinative obituaries. However, there appear here to be possible conceptual relationships between CONTAINER and 
Author accepted preprint

McGlashan, M. (2021) Networked discourses of bereavement in online COVID-19 memorials. International

Journal of Corpus Linguistics. 26(4)

JOURNEY/DEPARTURE mappings that have thus far gone underexplored in the literature on bereavement discourse whereby the deceased is a passive thing/object that is to be contained and that their journey/departure is the result of having been taken from the bereaved. This metaphorical formulation makes absent some agentive, forcible taker which could be read in this context as being COVID-19 as the disease causing the untimely taking but may figure more generally within bereavement discourse as a way for the bereaved - as the taken from - to signify an unwilling parting with the deceased and to hold accountable (without directly identifying) a cause of death.

\section{Conclusion}

This paper applied corpus methods to examine frequent and networked linguistic features found in a large corpus of online memorials. Using network graphs to visualise co-occurrence between frequent features in a corpus enables not only the observation of the frequency of those features but also the ability to identify recurrent networks of co-occurrence between multiple features across multiple texts. Networks such as these can provide corpus linguists with another "way into" the observance of linguistic frequencies and relationships within a corpus and, thus, for CADS researchers how these features and relationships function within discourse.

With respect to RQ1, the work, identifies specific linguistic features (types, lemmata, and ngrams) that are used prevalently across these online memorials vis-à-vis relational identities, love, loss, time, and memory, and finds that these features function within wider networked relationships. These relationships - cumulative, repeated, and meaningful patterns of co-occurrence between linguistic features which link, for example, ideas of time, love, memory, etc. - begin to reveal some prominent linguistic networks that perform important discursive and social functions (RQ2). For example, representations and constructions of death and bereavement in the online memorials studied reveal a predominance of opinative as opposed to informative discourse (Crespo-Fernández, 2007), including the avoidance of semantically negative language and the use of metaphors, especially related to the veiling or "denial of death" (Crespo-Fernández, 2011). The marked absence of direct references to COVID-19 as a biophysical aspect of death is especially prominent here which, through its absence, provides further evidence of the importance of death-resistant language (Phillips, 2007) to bereavement discourse. Moreover, the markedly high frequency of reference to relational identities gives evidence that the bereaved take a greater interest in the favourable 
Author accepted preprint

McGlashan, M. (2021) Networked discourses of bereavement in online COVID-19 memorials. International

Journal of Corpus Linguistics. 26(4)

(re)articulation and (re)construction of relationships with, and the relational identities of, decedents. Not only do these memorials recast social identities and relations, but they also represent linguistic and discursive (re)instantiations of bereavement and death as socially mediated practices, which frame (Bonsu, 2007: 206) their objects of representation in terms of normative and desirable social ideals of love and (family) relationships, especially. Such framing simultaneously sanitises undesirable specifics of the dead (both their lives and deaths) whilst potentially revealing insights into hegemonic ideals of what it means to have lived a "good" life.

Sadly the fact that the COVID-19 pandemic is ongoing means that https://www.rememberme2020.uk/ is being continuously updated with new memorials and has regrettably grown in size since data were collected for this study. The growth of this particular memorial and of scholarly interest in online bereavement suggests that online memorials like https://www.rememberme2020.uk/ are becoming significant cultural sites for remembrance, the importance of which appears to have grown during the COVID-19 pandemic due to the inability to mourn collectively in a physical environment. The study of such sites, therefore, represents an important endeavour for understanding (evolving) social practices of mourning. As such, it is hoped that the present paper makes some contribution to understanding of the language and social practices of online memorials, as well as offering analytical methods with which to understand others in the future.

\section{Acknowledgements}

I thank the reviewers and editors for their constructive feedback on earlier drafts of this paper.

\section{References}

Alali, A. O. (1994). The disposition of Aids imagery in New York Times' Obituaries. OMEGA - Journal of Death and Dying, 29(4), 273-289.

Anderson, K. A., \& Han, J. (2008). An exploration of ageism and sexism in obituary photographs: 1967-1997. OMEGA - Journal of Death and Dying, 58, 335-45.

Baker, P. (2006). Using Corpora in Discourse Analysis. Continuum.

Baker, P. (2014). Using Corpora to Analyze Gender. Bloomsbury. 
Author accepted preprint

McGlashan, M. (2021) Networked discourses of bereavement in online COVID-19 memorials. International Journal of Corpus Linguistics. 26(4)

Baker, P. (2016). The shapes of collocation. International Journal of Corpus Linguistics, 21(2), 139-164.

Baker, P., Gabrielatos, C., KhosraviNik, M., Krzyżanowski, M., McEnery, T., \& Wodak, R. (2008). A useful methodological synergy? Combining critical discourse analysis and corpus linguistics to examine discourses of refugees and asylum seekers in the UK press. Discourse \& Society, 19(3), 273-306.

Baker, P., \& McEnery, T. (2015). Corpora and Discourse Studies. Palgrave Macmillan.

Baker, P., \& McGlashan, M. (2020). Critical Discourse Analysis. In S. Adolphs \& D. Knight (Eds.), The Routledge Handbook of English Language and the Digital Humanities (pp. 220-241). Routledge.

Bell, J., Bailey, L., \& Kennedy, D. (2015). 'We do it to keep him alive': Bereaved individuals' experiences of online suicide memorials and continuing bonds. Mortality, 20(4), 375-389.

Benoit, K., Watanabe, K., Wang, H., Nulty, P., Obeng, A., Müller, S., \& Matsuo, A. (2018). quanteda: An R package for the quantitative analysis of textual data. Journal of Open Source Software, 3(30), 774.

Bonsu, S. (2007). The presentation of dead selves in everyday life: Obituaries and impression management. Symbolic Interaction, 30(2), 199-219.

Brezina, A., McEnery, T., \& Wattam, S. (2015). Collocations in context: A new perspective on collocation networks. International Journal of Corpus Linguistics, 20(2), 139-73.

Brookes, G., \& McEnery, T. (2020) Correlation, collocation and cohesion: A corpus-based critical analysis of violent jihadist discourse. Discourse \& Society, 31(4), 351-373.

Charteris-Black, J. (2006). Britain as a container: Immigration metaphors in the 2005 election campaign. Discourse \& Society, 17(5), 563-581.

Crespo-Fernández, E. (2006). The language of death: euphemisms and conceptual metaphorization in Victorian obituaries. SKY Journal of Linguistics, 101-130.

Crespo-Fernández, E. (2007). Linguistic devices coping with death in Victorian obituaries. Revista Alicantina de Estudios Ingleses, 20, 7-21.

Crespo-Fernández, E. (2011). Euphemistic conceptual metaphors in epitaphs from Highgate Cemetary. Review of Cognitive Linguistics, 9, 198-225.

Crespo-Fernández, E. (2013). Euphemistic metaphors in English and Spanish epitaphs: A comparative study. ATLANTIS Journal of the Spanish Association of Anglo-American Studies, 35(2), 99-118. 
Author accepted preprint

McGlashan, M. (2021) Networked discourses of bereavement in online COVID-19 memorials. International Journal of Corpus Linguistics. 26(4)

Davis, C. S., Quinlan, M. M., \& Baker, D. K. (2016). Constructing the dead: Retrospective sensemaking in eulogies. Death Studies, 40(5), 316-328.

de Vries, B., \& Rutherford, J. (2004). Memorializing loved ones on the World Wide Web. OMEGA - Journal of Death and Dying, 49(1), 5-26.

DeGroot, J. M. (2014). "For whom the bell tolls": Emotional rubbernecking in Facebook memorial groups. Death Studies, 38(2), 79-84.

Dennis, M. R., \& Kunkel, A. D. (2004). Fallen heroes, lifted hearts: Consolation in contemporary presidential eulogia. Death Studies, 28(8), 703-731.

Doka, K. L. (1987). Silent sorrow: Grief and the loss of significant others. Death Studies, $11(6), 455-469$.

Ergin, M. (2012). Religiosity and the construction of death in Turkish death announcements, 1970-2009. Death Studies, 36(3), 270-291.

European Centre for Disease Prevention and Control. (2021). Data on 14-day notification rate of new COVID-19 cases and deaths. Retrieved May 27, 2021, from https://www.ecdc.europa.eu/en/publications-data/data-national-14-day-notificationrate-covid-19

Fairclough, N. (2003). Analysing Discourse: Textual Analysis for Social Research. Routledge.

Flowerdew, L. (2014). Corpus-based discourse analysis. In J. P. Gee \& M. Handford (Eds.), The Routledge Handbook of Discourse Analysis (pp. 174-187). Routledge.

Fries, U. (1990). Two hundred years of English death notices. In M. Bridges (Ed.), On Strangeness (pp. 57-71). Gunter Naar.

Gabrielatos, C. (2020). DOCS Bibliography. Retrieved September 10, 2021, from https://www.edgehill.ac.uk/englishhistorycreativewriting/staff/dr-costasgabrielatos/?tab=docs-bibliography

Giaxoglou, K. (2015). 'Everywhere I go, you're going with me': Time and space deixis as affective positioning resources in shared moments of digital mourning. Discourse, Context \& Media, 9, 55-63.

Halbur, B. \& Vandagriff, M. (1987). Societal responses after death: a study of sex differences in newspaper death notices for Birmingham, Alabama, 1900-1985. Sex Roles, 17, 421-36.

Harvey, J. H. (1996). Embracing the Memory: Loss and the Social Psychology of Storytelling. Allyn \& Bacon. 
Author accepted preprint

McGlashan, M. (2021) Networked discourses of bereavement in online COVID-19 memorials. International

Journal of Corpus Linguistics. 26(4)

Heynderickx, P. C., \& Dieltjens, S. M. (2016). An analysis of obituaries in staff magazines.

Death Studies, 40(1), 11-21.

Hirji, S., Hirji, A., \& Lakasing, E. (2020). The Impact of COVID-19 on Islamic Burial Rites.

Geriatric Medicine Journal. Retrieved September 10, 2021, from

https://www.gmjournal.co.uk/the-impact-of-covid-19-on-islamic-burial-rites

Jones, S. (2004). 404 not found: The internet and the afterlife. OMEGA - Journal of Death and Dying, 48(1), 83-88.

Kunkel, A. D., \& Dennis, M. R. (2003). Grief consolation in eulogy rhetoric: An integrative framework. Death Studies, 27, 1-38.

Lakoff, G. (1993). The contemporary theory of metaphor. In A. Ortony (Ed.), Metaphor and Thought ( $2^{\text {nd }}$ ed.; pp. 202-251). Cambridge University Press.

Lingel, J. (2013). The digital remains: Social media and practices of online grief. The Information Society, 29(3), 190-195.

Marchi, A., \& Taylor, C. (2018). Introduction: Partiality and reflexivity. In C. Taylor \& A. Marchi (Eds.), Corpus Approaches to Discourse: A Critical Review (pp. 1-15). Routledge.

McEnery, T., \& Hardie, A. (2012). Corpus Linguistics: Method, Theory and Practice. Cambridge University Press.

McEnery, T., Xiao, R., \& Tono, Y. (2006). Corpus-Based Language Studies: An Advanced Resource Book. Routledge.

Meyrowitz, J. (1994). The life and death of media friends: New genres of intimacy and mourning. In R. Cathcart \& S. Drucker (Eds.), American Heroes in the Media Age (pp. 62-81). Hampton Press.

Neimeyer, R. A. (1998). Lessons of Loss: A Guide to Coping. McGraw-Hill.

Neimeyer, R. A., Klass, D., \& Dennis, M. R. (2014). A social constructionist account of grief: loss and the narration of meaning. Death Studies, 38(8), 485-498.

Neimeyer, R. A., Prigerson, H. G., \& Davies, B. (2002). Mourning and Meaning. American Behavioral Scientist, 46(2), pp. 235-51.

Partington, A. (2004). Corpora and discourse, a most congruous beast. In A. Partington, J.

Morley, \& L. Haarman (Eds.), Corpora and Discourse (pp. 11-20). Peter Lang.

Philip, G. (2017). Conventional and novel metaphors in language. In E. Semino \& Z. Demjén (Eds.), The Routledge Handbook of Metaphor and Language (pp. 219-232).

Routledge. 
Author accepted preprint

McGlashan, M. (2021) Networked discourses of bereavement in online COVID-19 memorials. International Journal of Corpus Linguistics. 26(4)

Phillips, J. B. (2007). The changing presentation of death in the obituary, 1899-1999. OMEGA - Journal of Death and Dying, 55(4), 325-346.

R Core Team (2020). R: A language and environment for statistical computing (Version 4.0.1.) [Computer software]. R Foundation for Statistical Computing. http://www.Rproject.org/

Refslund Christensen, D., \& Gotved, S. (2015). Online memorial culture: An introduction. New Review of Hypermedia and Multimedia, 21(1-2), 1-9.

Roberts, P. (2004). Here today and cyberspace tomorrow: Memorials and bereavement support on the Web. Generations: Journal of the American Society on Aging, 28(2), $41-46$.

Rodler, C. K. E., \& Hölzl, E. (2002). Gender stereotypes of leaders: An analysis of the contents of obituaries from 1974 to 1998. Sex Roles, 45(11), 827-843.

Roque Ramírez, H. N. (2010). Gay latino histories/dying to be remembered. In G. Perez, F. Guridy, \& A. Burgos (Eds.), Beyond el Barrio: Everyday Life in Latina/o America (pp. 103-128). New York University Press.

Sunderland, J. (2004). Gendered Discourses. Palgrave Macmillan.

The New York Times (2021). Those We've Lost. [online] Available at: https://www.nytimes.com/interactive/2020/obituaries/people-died-coronavirusobituaries.html [accessed 10/09/2021]

Time Staff (2021). The Lives Lost to Coronavirus. [Online] Available at: https://time.com/5814406/coronavirus-obituaries/ [accessed 10/09/2021]

Tognini-Bonelli, E. (2001). Corpus Linguistics at Work. John Benjamins.

van Leeuwen, T. (2008). Discourse and Practice: new tools for critical discourse analysis. Oxford University Press.

Walter, T. (2015). Communication media and the dead: From the stone age to Facebook. Mortality, 20(3), 215-232.

Wickham, H. (2021). rvest: Easily Harvest (Scrape) Web Pages (Version 1.0.1). [Computer software]. https://CRAN.R-project.org/package=rvest

Williams, J. E. (1997). Discourses on death: Obituaries and the management of spoiled identity. OMEGA - Journal of Death and Dying, 34(4), 301-319.

Williams, J. E. (2003). Obituaries. In C. D. Bryant (Ed.), Handbook of Death and Dying (pp. 694-702). Sage. 
Author accepted preprint

McGlashan, M. (2021) Networked discourses of bereavement in online COVID-19 memorials. International Journal of Corpus Linguistics. 26(4)

Wright, D., \& Brookes, G. (2019). 'This is England, speak English!': A corpus-assisted critical study of language ideologies in the right-leaning British press. Critical Discourse Studies, 16(1), 56-83.

\section{Address for correspondence}

Mark McGlashan

School of English, Birmingham Institute of Media and English

Birmingham City University

Birmingham, B4 7XG

United Kingdom

Mark.McGlashan@bcu.ac.uk 